\title{
Upaya Menumbuhkan Karakter Peduli Lingkungan Melalui Kajian Konsep Fisika Pada Arsitektur Kearifan Lokal Budaya Sumatera Barat
}

\author{
Renol Afrizon ${ }^{1)}$, Letmi Driwidal ${ }^{2)}$ \\ 1) Jurusan Fisika, FMIPA Universitas Negeri Padang \\ 2) Jurusan Fisika, FMIPA Universitas Negeri Padang \\ afrizon@fmipa.unp.ac.id
}

\begin{abstract}
The utilization of local wisdom in presentation of physics material of high school grade XI by physics education students is still not optimal. This indicates that the students who careless by sense of environmental. Physics learning resources in daily activities such as local wisdom needed to provide. The purpose of this study is to explore the application of physics concepts to local wisdom of West Sumatra culture as an effort to improve the character of environmental care. The type of research is qualitative research with survey method. Data collected by questionnaires, interviews, document analysis, field notes and Focus Group Discussion (FGD). Analyzed techniques of data which be used qualitative data techniques with steps are data reduction, presentation, conclusion and verification as data analyzed techniques. Result of the research is physics concepts of Rumah Gadang. First, although the Rumah Gadang roof was made of palm fiber but it still survive from leakage problems and wind exposure. The functions of the roofing of the Rumah Gadang are: (1) to increase the speed of the rain falling into the roof, (2) minimize the momentum on the roof, (3) projecting the force of the wind in all directions so that the wind is not trapped on the roof of the Rumah Gadang, 4) made of adhesive between kitchen ash with a good palm fiber (deep layer of palm fiber), and 5) water deposition on the bad side of palm fiber (outer layer of palm fiber) so that it will be rise to back the surface of the roof through the capillarity mechanism. Second, the wall with a hollow layer can reduce the heat from outside the walls during the day so the air in the room is not as hot as the outside and the heat that has flowing in the room will be trapped by the wall so that air is not too cold at the night. Third, old pole serves as a reference to determine the equalibrium of Rumah Gadang and the poles are made with a slope which opposite direction on two sides (left and right house). This can be create a stable of equalibrium Rumah Gadang. Fourth, a stone of fondation that has a diameter greater than the diameter of the milestone can serve to minimize the fictive forces generated by the soil due to the occurrence of the earthquake. Fifth, the staircase made with a certain slope provides a distinct mechanical advantage for the visitor where the where the produced work made becomes as easier. The conclusions of this research indicates this study provide one of the efforts to improve the character of environmental care in physics learning.
\end{abstract}

Keywords : Physics material, Local wisdom, Character of environmental care

This is an open access article distributed under the Creative Commons 4.0 Attribution License, which permits unrestricted use, distribution, and reproduction in any medium, provided the original work is properly cited $\odot 2018$ by author and Universitas Negeri Padang.

\section{PENDAHULUAN}

Kemendikbud (2016: 8-9) menjelaskan bahwa proses pembelajaran fisika dengan pen dekatan ilmiah berbasis keilmuan memiliki maksud agar: 1) peserta didik tahu tentang 'mengapa' (ranah sikap), 2) peserta didik tahu tentang 'apa' (ranah pengetahuan), dan peserta didik tahu tentang 'bagaimana' (ranah keteram pilan). Hasil akhir pembelajaran fisika yang di harapkan adalah terjadi peningkatan dan ke seimbangan antara kemampuan untuk menjadi manusia yang baik (soft skills) dan manusia yang memiliki kecakapan dan pengetahuan untuk hidup secara layak (hard skills) dari peserta didik yang meliputi aspek kompetensi sikap, keterampilan, dan pengetahuan. Hal ini sesuai dengan Gambar 1.

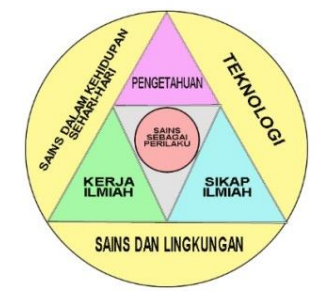

Gambar 1. Kerangka Pengembangan IPA

(Kemendikbud (2016: 3)) 
Pembelajaran fisika juga harus memuat isu global misalnya perubahan iklim, pemanasan global, sumberdaya energi, energi alternatif, dan perkembangan teknologi digital (Kemendikbud, 2016: 9-10). Kegiatan pembelajaran fisika juga perlu diperkaya dan diperluas dengan sumber daya yang ada di daerah/sekolah. Pembelajaran fisika harus memanfaatkan objek dan fenomena yang terjadi di lingkungan terdekat dengan pe serta didik dan guru. Salah satu objek dan sumber belajar yang dekat dengan peserta didik dan guru adalah kearifan lokal.

Namun, kenyataanya mahasiswa pendidi kan fisika sebagai calon guru belum optimal memanfaatkan sumber belajar yang ada dalam kehidupan sehari-hari dan dekat dengan peserta didik dalam penyajian materi fisika pada perku liahan fisika SMA/MA dan SMK kelas XI pada semester Januari-Juni 2017. Hasil analisis ang ket yang diberikan di akhir perkuliahan tersaji pada Gambar 2 dan Gambar 3.

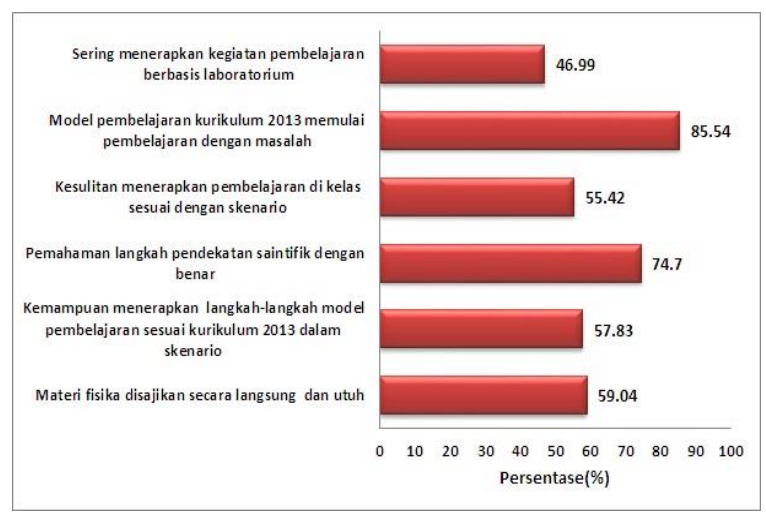

Gambar 2. Hasil Analisis Penyajian Materi Fisi ka dalam Pembelajaran di Kelas (Sumber: Afrizon, 2017: 1219)

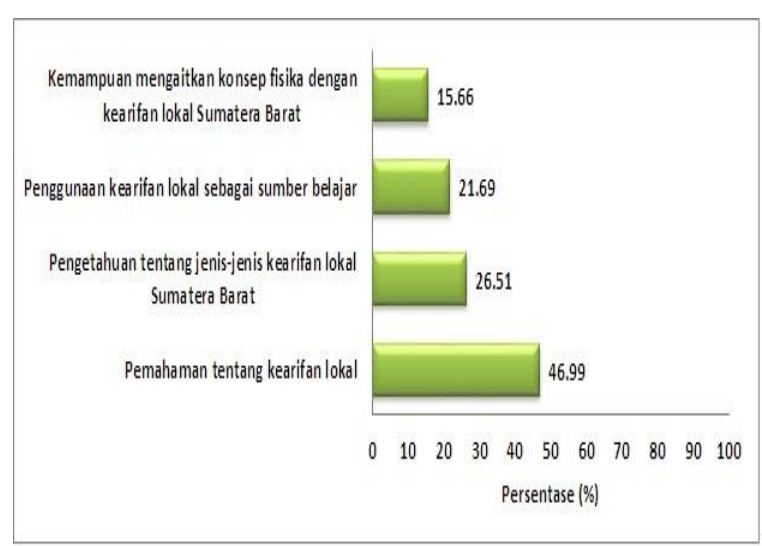

Gambar 3. Hasil Analisis Pemanfaatan Kearifan Lokal sebagai Sumber Belajar (Sumber: Afrizon, 2017: 1220)
Gambar 2 memperlihatkan 85\% lebih mahasiswa memahami model pembelajaran yang dianjurkan kurikulum 2013 yang berawal dari permasalahan dalam kehidupan sehari-hari. 55\% mahasiswa diantaranya mampu merancang skenario pembelajaran sesuai tuntutan kuriku lum 2013 tetapi sulit untuk menerapkannya di kelas. Gambar 3 menunjukkan bahwa peman faatan kearifan lokal dalam kegiatan pembelaja ran fisika rendah. Hal ini mengindikasikan bah wa rasa kepedulian terhadap lingkungan sekitar belum tumbuh pada diri mahasiswa calon guru. Salah satu solusi yang ditawarkan adalah pe nyediaan sumber belajar yang mengandung kearifan lokal budaya Sumatera Barat.

Doddy Soedigdo, Ave Harysakti, dan Tari Budayanti Usop (2014: 38-40) mengemukakan wujud kearifan lokal dapat dikategorikan ke da lam dua aspek. Kearifan lokal tangible (berwu jud fisik) meliputi: 1) kearifan lokal yang ter tuang dalam bentuk catatan tertulis seperti primbon dan praksi, 2) karya-karya arsitektur/ bangunan tradisional seperti rumah gadang, dan 3) benda cagar budaya, karya seni/kerajinan tangan tradisional misalnya keris, batik, saluang, bansi, pupuik batang padi, talempong, dan ra bab. Sedangkan, kearifan lokal intangible (tidak berwujud) meliputi petuah-petuah yang disampai kan secara verbal dan turun-temurun dapat berupa nyanyian, kidung yang mengandung aja ran-ajaran tradisional, dan tari-tarian misalnya tari piring dan tari payung.

Kearifan lokal yang ada lahir dari kesela rasan wujud arsitektur dengan alam. Hal ini da pat dilihat dari kemampuan bangunan kearifan lokal untuk bertahan meskipun zaman telah berubah. Keselarasan hubungan ini tersaji pada Gambar 4.

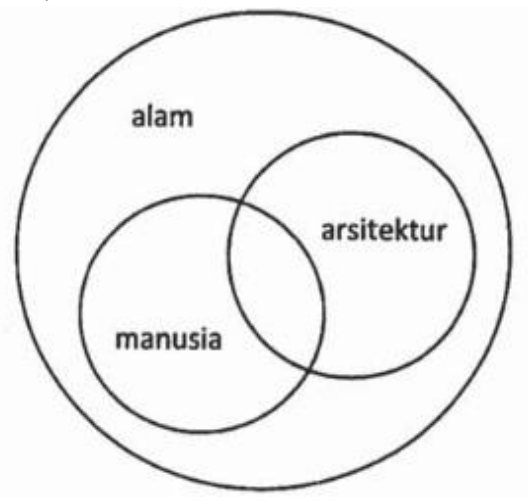

Gambar 4. Skema Hubungan Manusia, Alam, dan Arsitektur (Sumber: Wikantiyoso, Respati dan Pindo Tutuko (2009: 21)) 
Gambar 4 menunjukkan bahwa manusia menghasilkan wujud arsitektur tanpa mengabai kan potensi-potensi yang yang dimiliki oleh alam dimana manusia itu berada. Alam menye diakan bahan-bahan yang dibutuhkan manusia dalam menghasilkan arsitektur sedangkan ma nusia memiliki peranan penting dalam menjaga alam. Alam, manusia dan arsitektur telah memi liki hubungan yang erat sejak zaman dahulu. Keselarasan hubungan ini dapat diungkap mela lui sebuah kajian konsep fisika. Kajian fisika pada kearifan lokal yang dilakukan secara men dalam dapat menjadi solusi bagi mahasiswa pendidikan fisika dalam menemukan referensi penerapan konsep fisika dalam kehidupan seha ri-hari dan dekat dengan mahasiswa. Bertitik tolak pada masalah yang telah diuraikan dapat dikemukakan bahwa konsep fisika pada bangu nan arsitektur kearifan lokal Sumatera Barat perlu dikaji melalui kegiatan penelitian. Tujuan dari penelitian adalah mengeksplorasi penerapan konsep fisika pada kearifan lokal budaya Suma tera Barat sebagai salah satu upaya menumbuh kan karakter peduli lingkungan.

\section{METODE PENELITIAN}

Penelitian yang dilaksanakan mengguna kan metode survei. Survei dapat dilakukan untuk berbagai penelitian yang bertujuan deskriptif, eksplanatif, dan eksploratif (Morrison, 2015: 165). Penelitian yang telah dilaksanakan berupa survei yang bertujuan deskriptif dan anali tis.Survei deskriptif sebagai survei pendahuluan perlu dilakukan sebelum kajian konsep fisika yang memuat unsur kearifan lokal Sumatera Barat dilaksanakan. Survei juga diberikan kepada masyarakat Sumatera Barat terkait struk tur rumah gadang yang asli. Survey analitis memiliki tujuan eksploratif dan eksplanatif. Penelitian yang bertujuan eksplorasi (penjelajah an) akan memperoleh gambaran mendasar berupa keterangan, informasi, dan data mengenai hal-hal yang belum diketahui. Penelitian yang bertujuan eksplanatif (bersifat menjelaskan sesuatu) berupaya menjawab pertanyaan "meng apa" (Morrison, 2015: 38).

Bangunan arsitektur berupa Rumah Ga dang di Kota Solok, Istano Basa Pagaruyuang dan Rumah Tuo Kampai Nan Panjang dijadikan objek penelitian. Penelitian yang bersifat kuali tatif ini memiliki sejumlah metode pengumpulan data seperti Focus Group Discussion (FGD), pengamatan lapangan, wawancara mendalam, dan studi kasus (Morrison, 2015: 26).

Setelah penelitian dilaksanakan maka akan terkumpul data penelitian. Tiga komponen yang digunakan untuk menganalisis data yang bersifat kualitatif menurut Miles, M.B dan A.M. Huberman, (1994: 12) yaitu: reduksi data, penyajian data, dan kesimpulan dan verifikasi. Me reduksi data berarti merangkum, memilih hal-hal yang pokok, memfokuskan pada hal-hal yang penting, dicari tema dan polanya dan membuang yang tidak perlu. proses reduksi data ini dilakukan oleh peneliti secara terus menerus saat melakukan penelitian untuk menghasilkan catatan-catatan inti dari data yang diperoleh dari hasil penggalian data. Penyajian data adalah sekumpulan informasi yang tersusun sehingga memberi kemungkinan adanya penarikan ke simpulan. Beberapa cara yang digunakan untuk menyajikan data yaitu: tabel, grafik, diagram lingkaran, bagan, digram venn, dan deskripsi berkaitan dengan data yang diteliti. Kesimpulan atau verifikasi adalah tahap akhir dalam proses analisis data. Penulis mengutarakan kesimpulan dari data-data yang telah diperoleh dan melak sanakan verifikasi melalui kegiatan FGD. Kegiatan ini untuk menganalisis konsep fisika yang terdapat pada arsitektur rumah gadang.

\section{HASIL DAN PEMBAHASAN}

\section{Hasil Penelitian}

Hasil penelitian ini berkaitan dengan persepsi masyarakat sumatera barat terkait struktur rumah gadang yang asli dan kajian konsep fisis nya.

\section{a. Hasil Persepsi Masyarakat Sumatera Ba rat terkait Struktur Rumah Gadang yang Asli}

Masyarakat yang diminta pendapatnya terkait struktur rumah gadang yang Asli berasal dari berbagai suku dan jabatan/gelar adat yang ada di Sumatera Barat. Responden berasal dari kabu paten Agam, kabupaten Lima Puluh Kota, kabu paten Tanah Datar, kabupaten Solok, dan kota Padang. Hasil persepsi masyarakat terkait struk tur rumah gadang yang asli mulai dari atap, dinding, tiang dan ruangan, sandi, dan tangga. Analisis angket tersaji pada Gambar 5, 6, 7, 8, dan 9. 


\section{1) Atap Rumah Gadang yang Asli}

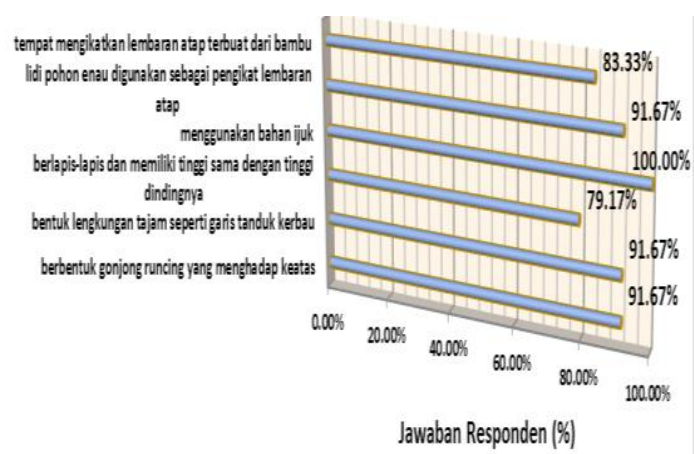

Gambar 5. Persepsi Masyarakat terkait Atap Rumah Gadang yang Asli

\section{2) Dinding Rumah Gadang yang Asli}

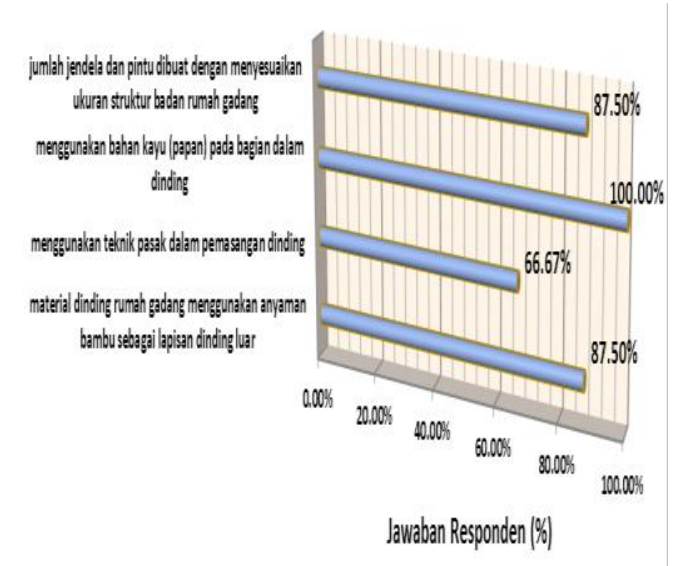

Gambar 6. Persepsi Masyarakat terkait Dinding Rumah Gadang yang Asli

\section{3) Tiang/Tonggak/Kolom dan Ruangan Gadang yang Asli}

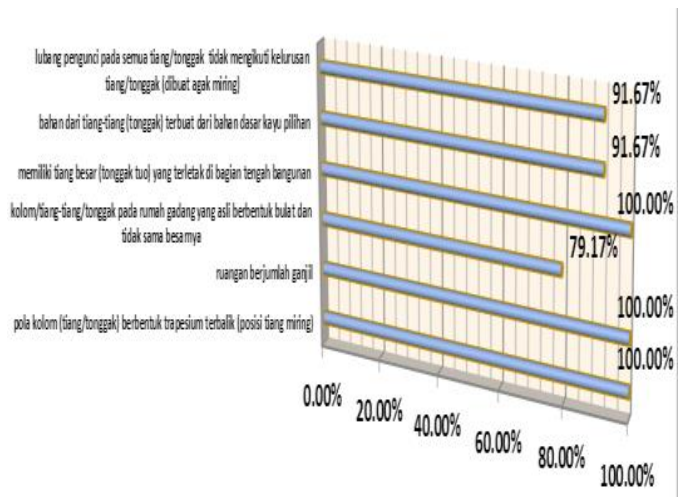

Jawaban Responden $(\%)$

Gambar7. Persepsi Masyarakat terkait Tiang/ Tonggak/Kolom dan Ruangan Rumah Gadang yang Asli

\section{4) Sandi Rumah Gadang yang Asli}

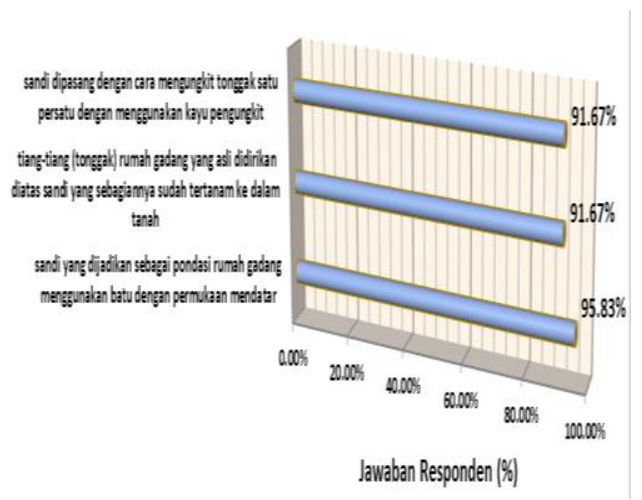

Gambar 8. Persepsi Masyarakat terkait Sandi Rumah Gadang yang Asli

\section{5) Tangga dan Dapur Gadang yang Asli}

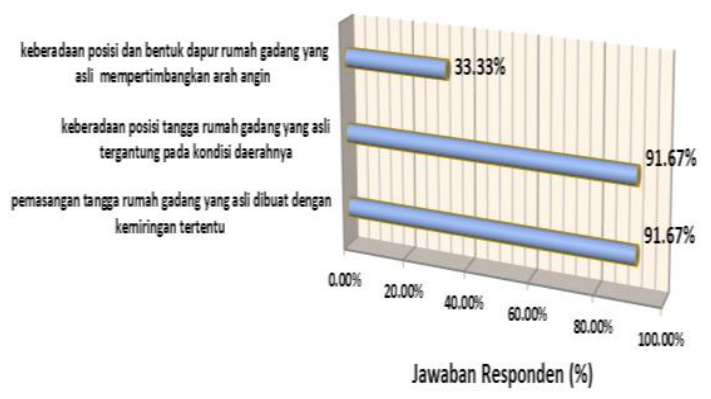

Gambar 9. Persepsi Masyarakat terkait Tangga dan Dapur Rumah Gadang yang Asli

Gambar 5 menunjukkan bahwa lebih 91\% masyarakat Sumatera Barat menyatakan bahwa atap rumah gadang yang asli terbuat dari ijuk dengan bentuk lengkungan tajam seperti garis tanduk kerbau dengan gonjong runcing yang menghadap ke atas. Gambar 6 menggambarkan bahwa lebih dari $87 \%$ masyarakat berpendapat dinding rumah yang asli menggunakan bambu sebagai material luar dinding dan kayu sebagai material dalam dinding. Selain itu, jumlah jen dela dan pintu dibuat dengan menyesuaikan struktur rumah gadang. Gambar 7 menunjukkan bahwa lebih $91 \%$ masyarakat berpendapat bah wa pola tiang rumah gadang yang asli berben tum trapesium terbalik dengan lobang pengunci dibuat miring dan tiang tuo berdiri di tengah bangunan sebelah kanan pintu utama. Tiang ter buat dari bahan kayu pilihan. Selain itu, ruangan pada rumah gadang berjumlah ganjil. Gambar 8 menunjukkan bahwa lebih dari $91 \%$ masyarakat setuju bahwa sandi rumah gadang yang asli ter buat dari batu dengan permukaan mendatar. 
Sandi dipasang dengan mengungkit tiang meng gunakan kayu pengungkit sehingga hanya seba gian kecil sandi tertanam ke dalam tanah. Gam bar 9 menunjukkan bahwa lebih dari $91 \%$ ma syarakat setuju bahwa posisi tangga rumah ga dang yang asli menyesuaikan kondisi daerahnya. Tangga dipasang dengan kemiringan tertentu.

\section{b. Hasil Kajian Fisis Struktur Rumah Gadang yang Asli \\ 1) Atap}

Atap rumah gadang memiliki lengkungan su dut lancip seperti garis tanduk kerbau jika dilihat dari sebelah depan. Jika dilihat lengkungan atap dari sebelah samping seperti sayap elang yang akan terbang. Lengkungan yang terlihat dari samping disebut "bubungan" seperti pada Gam bar 10. Bagian tertinggi dari setiap ujung atap dibuat runcing danmenghadap ke atas. Ujung gonjong (penahan gonjong) dibalut dengan timah. Atap rumah gadang yang meng gunakan bahan ijuk dibuat berlapis-lapis. Susunan lapi san atap ijuk mulai dari bagian terdalam hingga bagian terluar terdiri atas: 1) saga jalin, 2) ijuk bagus yang digulung, 3) saga jalin, dan ijuk jelek yang digulung. Lapisan atap ini harus di bungkus selama 6 bulan setelah atap dipasang.

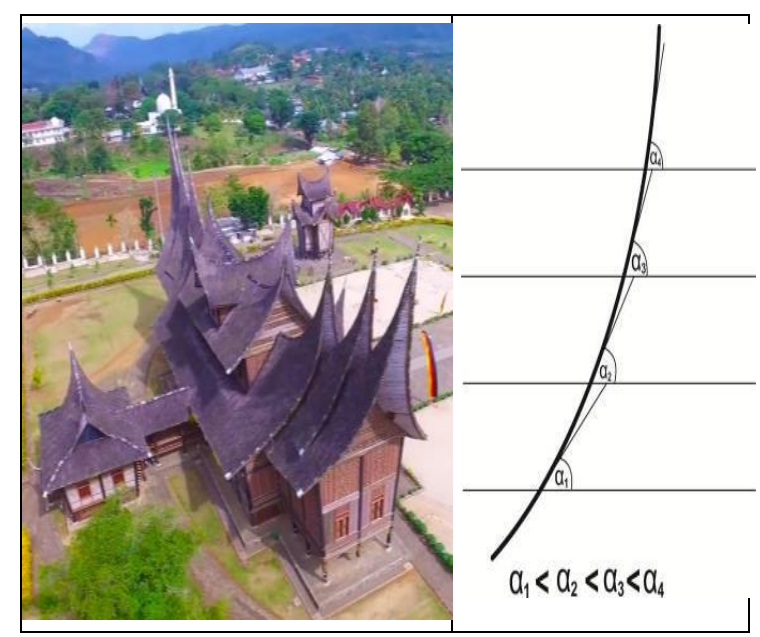

Gambar 10. Atap Rumah Gadang

Meskipun atap rumah gadang terbuat dari ijuk tapi tetap bertahan dari masalah kebocoran dan terpaan angin. Hal ini disebabkan karena desain atap rumah gadang memiliki beberapa fungsi secara fisis, diantaranya: (1) memperbe sar kecepatan aliran air hujan yang jatuh ke atap, (2) memperkecil momentum pada atap, (3) mengurai gaya tekan angin ke segala arah se hingga angin tidak terperangkap pada atap rumah gadang, (4) terciptanya sifat adhesif abu dapur dengan ijuk yang bagus (ijuk lapisan dalam), dan (5) air yang mengendap pada ijuk yang jelek (ijuk lapisan luar) akan naik kembali ke permukaan atap melalui mekanisme kapilaritas.

\section{2) Dinding}

Dinding pada rumah gadang terdiri dari din ding depan dan dinding belakang. Dinding ba gian depan terbuat dari material kayu. Sedang kan, dinding bagian belakang terbuat dari lapisan yang berongga dengan material anyaman bambu pada lapisan luardan kayu/papan yang diberi ukiran yang memiliki makna-makna tertentu pada lapisan dalam. Hal ini tersaji jelas pada Gambar 11.

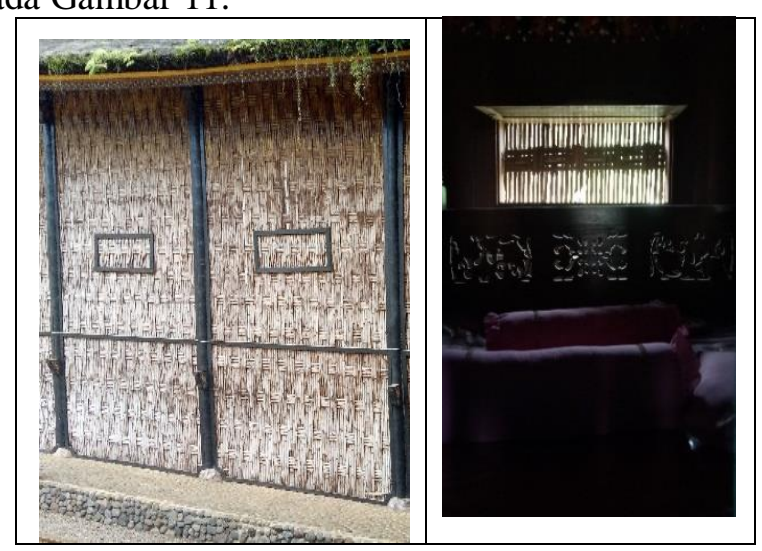

Gambar 11. Dinding Rumah Gadang

Pemberian anyaman bambu pada lapisan luar dinding dapat menjaga dan melindungi rumah dari sinar matahari dan rembesan air hujan saat hujan deras. Dinding dengan lapisan berongga ini terletak berdekatan dengan kamar. Dinding dengan lapisan berongga mampu mere dam kalor yang masuk dari luar dinding pada siang hari sehingga udara di dalam kamar tidak sepanas udara luar dan kalor yang sudah menga lir dalam kamar akan terperangkap oleh dinding sehingga udara pada kamar tidak terlalu dingin pada malam hari.

\section{3) Tiang/Tonggak/Kolom}

Tiang rumah gadang memiliki bentuk tidak bulat dan terbuat dari kayu pilihan pada gambar 12 (a) dan (b). Tiang pada rumah gadang terdiri atas tiang tuo, tiang tapi, tiang temban, tiang tengah, tiang bilik, dan tiang dapur. Tiang pertama yang didirikan dan terletak disebelah kanan pintu utama dikenal dengan tiang tuo. Tiang tuo berfungsi sebagai acuan menentukan keseimbangan pada rumah gadang. 


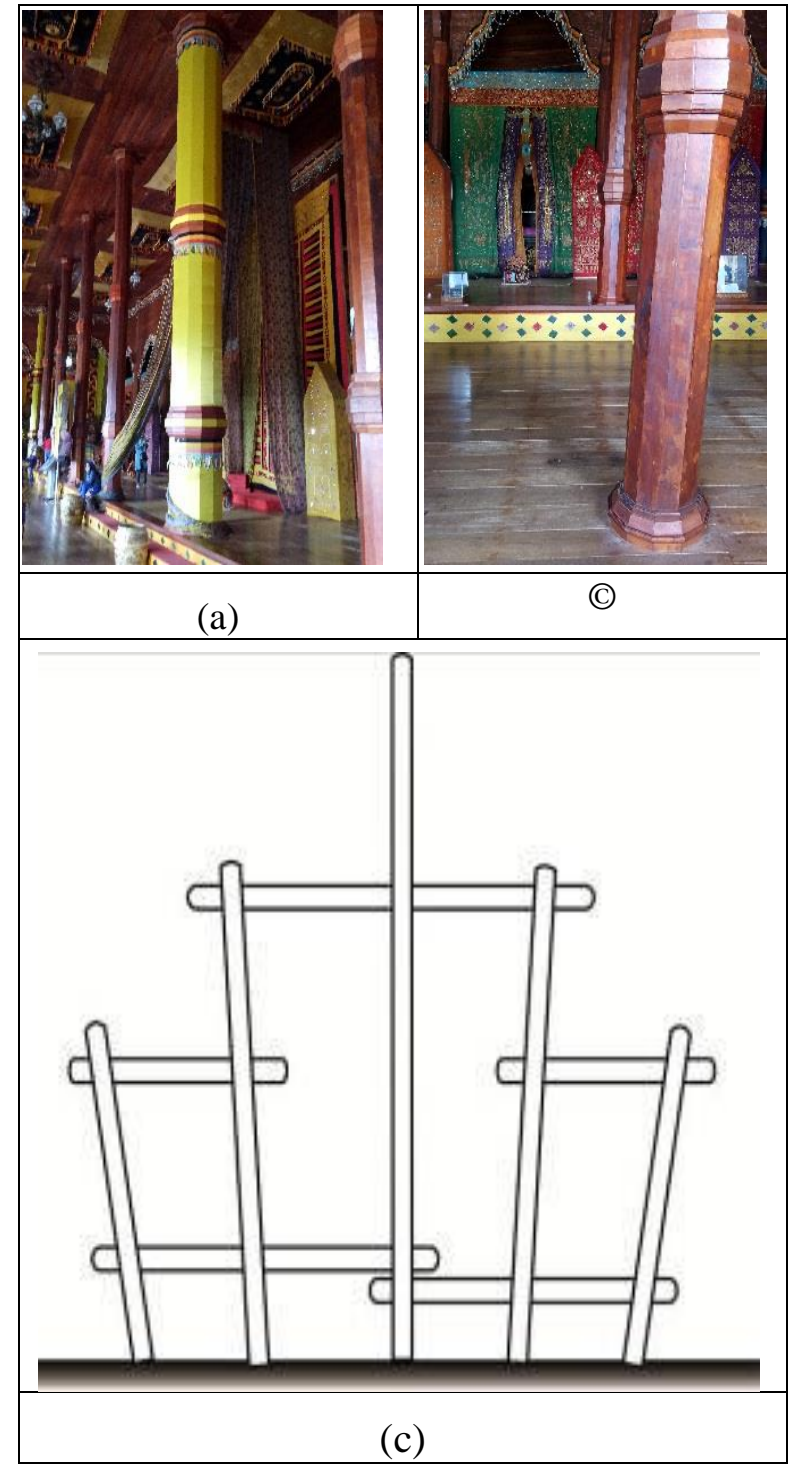

Gambar 12. Tiang Rumah Gadang

Tiang-tiang dibuat dengan kemiringan yang berlawanan arah pada dua sisi (kiri dan kanan rumah) seperti gambar 12 (c). Hal ini dapat menciptakan keseimbangan stabil pada rumah gadang. Tiang-tiang yang dibuat miring membuat pola kolom seperti trapesium terbalik. Rangkaian tiang tersambung satu sama lain menggunakan pasak berlawanan arah dengan arah sambungan. Pasak memiliki bahan yang sama dengan tiang. Hal ini bertujuan agar efek elastisitas bahan menjadi sama besar antara sambungan dengan pasak sehingga tiang menja di terangkai dengan kuat dan stabil.

\section{4) Sandi}

Sandi merupakan batu sungai yang pipih dan memiliki permukaan mendatar. Sandi digu nakan sebagai pondasi pada rumah gadang. Pe masangan sandi pada rumah gadang berbeda dengan pondasi pada rumah biasa. Sandi rumah gadang dipasang setelah rangka rumah selesai. Pemasangan sandi dilakukan dengan cara meng ungkit tonggak menggunakan tuas yang disebut "kalang patiang". Hal ini terlihat pada Gambar 13 (a).

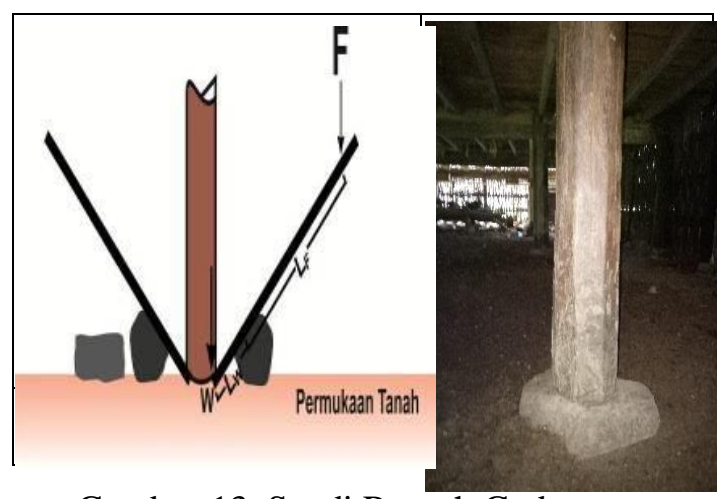

Gambar 13. Sandi Rumah Gadang

Sandi yang memiliki diameter lebih besar daripada diameter tonggak seperti Gambar 13 (b) berfungsi memperkecil gaya fiktif yang muncul oleh tanah akibat terjadinya gempa. Hal ini dika renakan sandi dapat mengikuti secara leluasa pola getaran gempa.

\section{5) Tangga}

Tangga pada rumah gadang terbuat dari bahan kayu dan biasanya diawali dengan batu alam yang datar. Tangga yang dibuat dengan kemiringan tertentu tersaji pada Gambar 14.

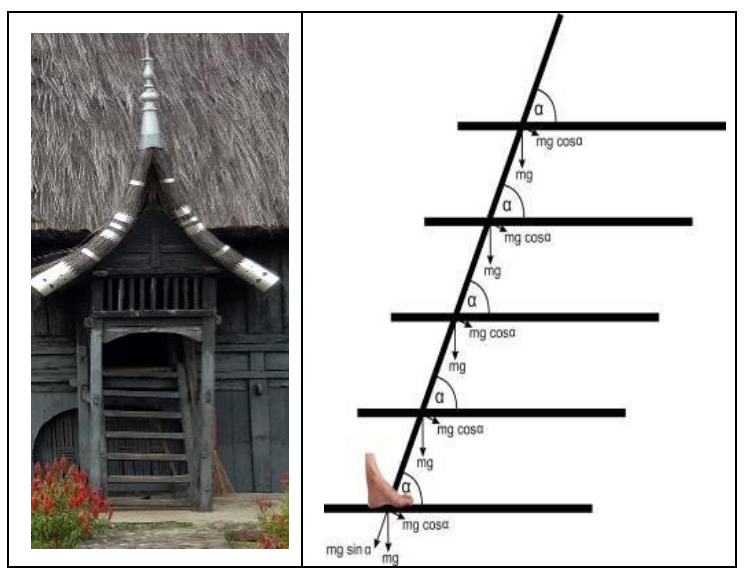

Gambar 14. Tangga Rumah Gadang

Anak tangga pada umumnya berjumlah ganjil dan sudut yang dibentuk oleh masingmasing anak tangga sama dengan sudut kemi ringan tangga. Hal ini memberikan keuntungan mekanistersendiri bagi pengunjung dimana usa ha yang dilakukan menjadi lebih mudah. 


\section{Pembahasan}

Bahan-bahan alami yang digunakan pada rumah gadang merupakan upaya orang minang kabau dalam mempersiapkan untuk pencegahan kerusakan lingkungan. Atap rumah mengguna kan bahan ijuk yang merupakan serat alami ter baik karena memiliki sifat tahan lama. Dinding yang terbuat dari bambu yang dianyam pada lapisan luar dan kayu pada lapisan dalam. Lapi san bambu dapat melindungi lapisan kayu pada dinding dari rembesan air hujan. Lapisan dinding ini mampu membuat cahaya matahari ma suk ke kamar secara maksimal. Selain itu, lapi san dinding juga mampu mendinginkan dan meng hangatkan ruangan kamar secara alami sehingga energi yang digunakan menjadi lebih efisien. Tiang dan tangga terbuat dari bahan kayu-kayu pilihan sehingga tidak mudah rapuh. Sandi yang terbuat dari batu kali dijadikan sebagai pondasi rumah gadang. Hasan (2004: 113) menjelaskan bahwa sandi rumah yang terbuat dari batu lebih baik daripada beton karena beton masih menyerap air sehingga dapat mempercepat pelapukan tiang. Hal ini juga sejalan dengan pendapat Noviarti, Ranti Irsa dan Astuti Madar (2013: 752) bahwa bangunan tradisional mi nangkabau lebih banyak dibangun dari bahanbahan alami. Bahan-bahan seperti kayu diguna kan untuk tiang, dinding, lantai, dan pola anya man dari gabungan bambu pada dinding logitu dinal di luar. Atapnya berbentuk seperti tanduk kerbau ditutupi bahan alami dari serat aren.

Desain rumah gadang yang mampu berta han terhadap bencana alam merupakan upaya orang minangkabau dalam melaksanakan kegiat an pencegahan kerusakan lingkungan. Saat ter jadi gempa bumi, tiang-tiang mampu mencipta kan keseimbangan stabil karena rangkaian tiang didesain berbentuk piramida terbalik. Selain itu, sandi yang berbentuk pipih juga berfungsi memperkecil gaya fiktif yang muncul oleh tanah sehingga tiang menjadi lebih fleksibel mengikuti pola gempa. Atap yang didesain melengkung mampu mengurai gaya tekan angin ke segala arah sehingga atap dapat bertahan ketika terjadi terpaan angin/badai. Desain atap juga mampu mampu memperbesar kecepatan aliran air hujan yang jatuh ke atap sehingga momentum yang terjadi pada atap menjadi lebih kecil. Air hujan yang masih mengendap pada ijuk lapisan luar dapat dipercepat proses penguapannya melalui mekanisme kapilaritas. Hal ini yang menyebab kan atap rumah gadang tidak bocor meskipun terjadi hujan lebat. Senada dengan pendapat yang dikemukakan oleh Purwanti Setijanti, Johan Silas, Sustyo Firmaningtyas, dan Hartatik (2012: A-61) bahwa bangunan tradisional minangkabau memiliki prinsip desain: 1) bangunan tahan gempa, 2) arsitektur tropis karena memiliki ciri utama pernaungan, 3) arsitektur hijau karena memperhatikan lingkungan sekitar dalam proses pembangunannya.

Bangunan tradisional minangkabau me miliki makna fisis yang terkandung didalamnya sehingga menimbulkan manfaat ketika mempe lajarinya. Dwiridal (2017: 1348) menjelaskan bahwa dengan mempelajari keteraturan alam melalui fisika, insyaAllah akan diperoleh hik mah atau dikenal dengan ilmu thabi'ah (watak keteraturan fisis alam). Bangunan tradisional minangkabau merupakan wujud kearifan lokal nyata yang menampilkan upaya manusia dalam melestarikan dan menghargai alam sekitarnya. Upaya yang dilakukan oleh orang minangkabau dalam mempersiapkan dan melaksanakan ber bagai kegiatan pencegahan kerusakan lingku ngan perlu diintegrasikan kedalam mata pelaja ran sehingga menumbuhkan karakter peduli lingkungan yang dapat ditularkan pada diri ma hasiswa calon guru dan peserta didik. Hal ini sesuai dengan yang dikemukakan oleh Puskur (2010: 18) yaitu salah satu cara merencanakan pengembangan nilai-nilai pendidikan dan karak ter budaya bangsa melalui pengintegrasian da lam mata pelajaran.

\section{KESIMPULAN}

Berdasarkan hasil penelitian dan pemba hasan dapat dinyatakan beberapa kesimpulan. Pertama, atap rumah gadang terbuat dari ijuk tapi tetap bertahan dari masalah kebocoran dan terpaan angin. Desain atap rumah gadang ber fungsi, diantaranya:(1) memperbesar kecepatan aliran air hujan yang jatuh ke atap, (2) memper kecil momentum pada atap, (3) mengurai gaya tekan angin ke segala arah sehingga angin tidak terperangkap pada atap rumah gadang, dan (4) terciptanya sifat adhesif abu dapur dengan ijuk yang bagus (ijuk lapisan dalam), dan 5) air yang mengendap pada ijuk yang jelek (ijuk lapisan luar) akan naik kembali ke permukaan atap melalui mekanisme kapilaritas. Kedua, dinding dengan lapisan berongga mampu meredam kalor yang masuk dari luar dinding pada siang hari sehingga udara di dalam kamar tidak sepanas udara luar dan kalor yang sudah mengalir dalam kamar akan terperangkap oleh dinding sehingga 
udara pada kamar tidak terlalu dingin pada ma lam hari. Ketiga, tiang tuo berfungsi sebagai acuan menentukan keseimbangan pada rumah gadang dan tiang-tiang yang dibuat dengan kemiringan yang berlawanan arah pada dua sisi (kiri dan kanan rumah). Hal ini dapat mencipta kan keseimbangan stabil pada rumah gadang. Keempat, sandi yang memiliki diameter lebih besar daripada diameter tonggak dapat berfungsi memperkecil gaya fiktif yang muncul oleh tanah akibat terjadinya gempa. Kelima, tangga dibuat dengan kemiringan tertentu memberikan keun tungan mekanis tersendiri bagi pengunjung di mana usaha yang dilakukan menjadi lebih mu dah. Hasil kajian menyajikan nilai-nilai kearifan lokal yang bersumber dari alam sehingga dapat menjadi salah satu upaya untuk menumbuhkan karakter peduli lingkungan dalam pembelajaran fisika.

\section{UCAPAN TERIMA KASIH}

Tulisan ini adalah bagian dari Hibah Peneli tian Dosen Pemula Tahun 2017 yang dibiayai oleh Dana PNBP Universitas Negeri Padang Tahun 2017. Penulis mengucapkan terimakasih kepada Rektor dan Ketua LP2M Universitas Negeri Padang yang telah memfasilitasi peneli tian ini. Ucapan terima kasih juga disampaikan kepada responden, tim survei lapangan dan pembantu peneliti yang telah membantu mendo kumentasikan hasil penelitian.

\section{DAFTAR PUSTAKA}

Afrizon, R. Hidayati, Rio A. 2017. Analisis Persepsi Mahasiswa Pendidikan Fisika terkait Pentingnya Pembelajaran Fisika Bermakna yang Menerapkan Unsur Kearifan Lokal Sumatera Barat. Prosiding Semirata 2017 Bidang MIPA BKS-PTN Wilayah Barat. Universitas Jambi. ISBN: 978-602-50593-0-8, Hal. 1214-1222.

Dwiridal, L. 2017. Upaya Menumbuhkan Sikap Religius dengan Mind Map Bernuansa
Hikmah Gravitasi pada Mekanika. Prosiding Semirata 2017 Bidang MIPA BKS-PTN Wilayah Barat. Universitas Jambi. ISBN: 978-602-50593-0-8, Hal. 1245-1356.

Doddy Soedigdo, Ave Harysakti, dan Tari Budayanti Usop. 2014. Elemen-Elemen Pendorong Kearifan Lokal pada Arsitektur Nusantara. Jurnal Perspektif Arsitektur, Vol. 9 No.1 hal: 37-47, ISSN: 1907 - 8536.

Hasan, H. 2004. Ragam Rumah Adat Minangkabau: Falsafah, Pembangunan, dan Kegunaan. Jakarta: Yayasan Citra Pendidikan Indonesia.

Kemendikbud. 2016. Silabus Mata Pelajaran Fisika Sekolah Menengah Atas/ Madrasah Aliyah (SMA/MA). Jakarta: Kementerian Pendidikan dan Kebudayaan.

Miles, M.B dan A.M. Huberman. 1994. Qualitative Data Analysis. California: SAGE Publications INC.

Morrison. 2015. Metode Penelitian Survei. Jakarta: Prenadamedia Group.

Noviarti, Ranti Irsa dan Astuti Madar.2013. Preserving Minangkabau traditional in West Sumatera, Indonesia: Integration of information technology. Procedia Environmental Science 17, Elsevier.

Purwanti Setijanti, Johan Silas, Sustyo Firmaningtyas, dan Hartatik. 2012. Eksistensi Rumah Tradisional Padang dalam Menghadapi Perubahan Iklim dan Tantangan Jaman. Simposium Nasional RAPI XI FT UMS.

Puskur. 2010. Pengembangan Pendidikan Budaya dan Karakter Bangsa. Jakarta: Puskur Balitbang Kementerian Pendidikan Nasional.

Wikantiyoso, Respati dan Pindo Tutuko. 2009. Kearifan Lokal dalam Perencanaan dan Perancangan Kota yang Berkelanjutan. Malang: Group Konservasi Arsitektur \& Kota. ISBN: 978-979-9488-43-5. 